\title{
The Jekyll and Hyde case of Nesidiocoris tenuis (Reuter) in the management of Bemisia tabaci (Gennadius) on tomato plants under greenhouse conditions
}

David Wari ( $\nabla$ davidwari9@gmail.com )

Ibaraki Agriculture Institute: Ibaraki-ken Nogyo Sogo Center https://orcid.org/0000-0003-0087-5141

Takeshi Saito

Ibaraki-ken Nogyo Sogo Center

Motonori Takagi

Ibaraki-ken Nogyo Sogo Center

Ryo Okada

Ibaraki-ken Nogyo Sogo Center

Takuya Miyamoto

Ibaraki-ken Nogyo Sogo Center

Toshiyuki Tezuka

Agri-soken Inc.

Masami Shimoda

National Agriculture and Food Research Organization

Takashi Ogawara

Ibaraki-ken Nogyo Sogo Center

\section{Research Article}

Keywords: Bemisia tabaci , Integrated pest management (IPM), Natural Enemy, Nesidiocoris tenuis,

Selective Pesticides, Violet-LEDs

Posted Date: May 12th, 2021

DOl: https://doi.org/10.21203/rs.3.rs-513406/v1

License: (9) (1) This work is licensed under a Creative Commons Attribution 4.0 International License.

Read Full License 


\section{Abstract}

The rise of Nesidiocoris tenuis (Reuter) as a natural enemy of various greenhouse pests in protected systems is widely reported around the globe, mainly in the Mediterranean basin, Asia, and North and Central America. In-vitro studies on improving its growth and reproduction using artificial and factitious diets, and banker plants for its breeding and propagation, and the use of violet-light (LEDs) as the attraction mechanism are well established. However, field studies are lacking in integrating these biological control components to promote $N$. tenuis predation on greenhouse pests. First, we performed toxicity assays in-vitro and in field conditions. Results revealed that neonicotinoids and spinosyns were toxic to $N$. tenuis. Avermectins \& milbemycins, pyridine azomethine derivatives and diamides, in contrast, were less to moderately toxic against $N$. tenuis but toxic to Bemisia tabaci, a known, widespread greenhouse pest. Field tests under greenhouse conditions were performed to evaluate the role of violetLEDs in relocating $N$. tenuis from banker plants to tomato plants and their augmentative effect on the densities of $B$. tabaci. Results showed that the movement of $N$. tenuis from banker plants to tomato plants was accelerated when supplemented with violet-LEDs. The accelerated resettlement of $N$. tenuis on tomato plants aided by selective pesticides significantly reduced $B$. tabaci egg, nymph and adult densities, densities that were relatively the same compared to those of the greenhouse with conventional pest control strategies. Overall, comparable outcomes in managing a pest are possible when biological control agents are integrated with environmentally safe and cost-effective approaches.

\section{Key Message}

- Nesidiocoris tenuis and its role as natural enemy of greenhouse pests is globally known. However, its compatibility with pesticides and its augmentation with biological control components in field studies are still lacking.

- Neonicotinoids and spinosyns were relatively toxic to tenuis nymphs and adults.

- Avermectins \& milbemycins, pyridine azomethine derivatives and diamides are less to moderately toxic against tenuis but toxic to greenhouse pest, Bemisia tabaci, therefore, can be used as selective pesticides to augment $N$. tenuis.

- Violet-LEDs enhanced relocation and establishment of tenuis from banker plants to tomato plants

- The successful tenuis reestablishment aided with selective pesticides suppressed $B$. tabaci densities.

\section{Introduction}

Integrated pest management (IPM) is a set of biological control components combined to maintain a pest population at levels below economic-threshold levels while conserving or promoting beneficial insects such as natural predators (Barzman et al. 2015). Successful integration of natural predators with other biological control components depends on thorough evaluation of biological control components that are involved in promoting natural predators. Biological control components such as banker plants, insectary plants, artificial diets, pheromones and et cetera have so far been documented to play a role in 
maximizing the predation potential of natural predators (NARO, 2019). In the Mediterranean agroecosystems, natural predators such as Macrolophus pygmaeus Rambur, Dicyphus maroccanus Wagner, Nesidiocoris tenuis Reuter (Hemiptera: Miridae), predatory mite Amblyseius swirskii AthiasHenriot (Acari: Phytoseiidae) and the minute pirate bug Orius laevigatus Fieber (Hemiptera: Anthocoridae) have been shown to be effective in controlling small arthropod pests such as sweet potato whitefly Bemisia tabaci Gennadius (Hemiptera: Aleyrodidae), the western flower thrips Frankliniella occidentalis Pergande (Thysanoptera: Thripidae) and aphids Myzus persicae Sulzer, Aphis gossypii Glover, Macrosiphum euphorbiae Thomas, and Aulacorthum solani Kaltenbach (Hemiptera: Aphididae) (Sanches 2008; Calvo et al. 2009; Perez-Hedo and Urbaneja, 2015). In North America, the native species, Dicyphus hesperus Knight, is commercially available and is used in temperate areas of Canada, Northern USA, and recently in Mexico to control several pests of tomato cultivated in greenhouses (Shipp and Wang, 2006; Calvo et al. 2016; Perez et al. 2020). In Asia, extensive studies have been in progress in the utilization of N. tenuis to control greenhouse pests such as whiteflies and aphids (Nakaishi et al. 2011; Nakano et al. 2016; Uehara et al. 2019; Yano et al. 2020; Owashi et al. 2019; Park and Lee, 2021).

Pesticides are an essential arm of IPM. Pest management using pesticides has been a success for many years, yielding satisfactory results. The success in managing pests with pesticides, however, is marred by high running costs of commercially mass-produced chemical insecticides, development of pest resistance and secondary outbreak of other pests, to name a few. Associated with the discussion at hand, pesticides can be toxic to the environment, to biological control agents such as natural predators, and to parasitoids. For pesticides and biological control agents to work effectively, selective or compatible pesticides are proposed. Choosing a selective or a compatible insecticide or selectively applying the pesticides are essential decisions in managing the given pest, at the same time preserving the biological control agents. However, choosing a selective or a compatible insecticide is a matter of gains and losses, pest status and its economic importance, labor and cost of control and the impact on the environment (Torres and Bueno, 2018). The prospect of using selective/compatible pesticides in combination with biological control agents is on the rise. In theory, chemical compounds, when used in combination with an effective natural enemy, may provide more comprehensive prophylactic and remedial treatments (Gentz et al. 2010). However, comprehensive studies are required to fully grasp the compatibility of insecticides and natural enemies for better results than either approach alone.

Nesidiocoris tenuis, a zoophytophagous mirid bug can prey on a variety of greenhouse pests such as whiteflies, aphids, thrips and some lepidopterans (Ghoneim, 2014). Previous reports have shown the use of $N$. tenuis as a natural enemy for major tomato pests such as tomato borer (Urbaneja et al. 2009) and whiteflies (Calvo et al. 2012). However, due to its zoophytophagous nature, N. tenuis also plant feeds when prey is scarce (Calvo et al. 2009). Damage to plants is expected from zoophytophagous mirid bugs, but the damage is always compensated for by the gain in pest suppression (Biondi et al. 2016). Previous studies have reported the integration of $N$. tenuis with biological control components to augment $N$. tenuis in suppressing greenhouse pests while feeding less on plants. To name a few, these include the use of resistant crops mediated by endophytic strain of Fusarium solani K that reduce $N$. tenuis plant feeding (Garantonakis et al. 2018); optimizing the initial density of $N$. tenuis when released to minimize 
plant feeding (NARO, 2019) and use of bunker plants for $N$. tenuis to breed and reproduce on (Huang et al. 2011). The use of banker plants has been successful in promoting $N$. tenuis breeding and proliferation, however, relocation from banker plants to crops is somewhat delayed as $N$. tenuis prefers banker plants to the crops (Saito et al. 2021). This delay in commercial crop production can be catastrophic if initial pest density is not managed. Several studies in the last decade have showed a spectrum of wavelength preferences that natural predators respond to (Shimoda and Honda, 2013; Ogino et al. 2016). Uehara et al. (2019) then investigated whether $N$. tenuis has a particular spectral preference. Their results showed that $N$. tenuis mostly preferred the violet light wavelength (peaking at $405 \mathrm{~nm}$ ). However, field studies are lacking to show the effectiveness of violet light as $N$. tenuis attraction and relocation mechanisms.

Tomato production in Japan is almost always under greenhouse conditions. However, tomato production is always marred by $B$. tabaci through herbivory damage and vectoring of viral diseases such as Tomato yellow leaf curl virus (TYLCV) and Tomato Chlorosis virus (ToCV). While pesticides are recommended for effective control, high costs and detrimental impacts on the surrounding environment and the natural enemies used in neighboring fields, as such, alternative means are being demanded by tomato farmers (Wari et al. 2020; Saito et al. 2021). In this study, we determine (i) the compatibility of insecticides and fungicides with $N$. tenuis by testing the toxicity and optimum lethal dose $\left(\operatorname{LD}_{50}\right)$ of the pesticides against different growth stages of $N$. tenuis; (ii) promotion of $N$. tenuis proliferation on banker plants; (iii) assess the movement of $N$. tenuis from banker plants to tomato plants when aided by a natural enemy attraction violet light-emitting diodes (hereafter as violet-LEDs); and (iv) the collective effect of $N$. tenuis, banker plants, violet-LEDs and selective pesticides on the population densities of $B$. tabaci.

\section{Materials And Methods}

\section{Plants and insect propagation}

Verbena cuttings (Verbena terena cv. Tapian) (Agri-soken Inc. Ibaraki, Japan), Sesame seeds (Sesamum indicum) (Sakata Seed Garden Center Ltd. Kanagawa, Japan) and Cleome plantlets (Cleome spinosa) (Proven Winners North America LLC. Illinois, USA) were propagated in the glasshouse at Ibaraki Horticultural Research Institute. Tomato seeds (Takii Seed Co., Ltd.) of Momotaro Peace cultivar, a TYLCV tolerant cultivar were used all throughout in the field studies. Nesidiocoris tenuis populations, supplied by Agri-soken Inc. (Ibaraki, Japan) were reared on verbena, sesame, and cleome at Ibaraki Horticultural Research Institute insectary rooms under optimized conditions $\left(25 \pm 1^{\circ} \mathrm{C}, 65 \pm 10 \% \mathrm{RH}\right.$, and 16:8 L:D photoperiod). Bemisia tabaci populations were originally collected from capsicum fields in Kamisu City (Ibaraki Prefecture, Japan) in 2011 and were sparingly maintained on eggplants (Solanum melongena), kidney bean (Phaseolus vulgaris L.), and green bell pepper (Capsicum annuum) as a food source at Ibaraki Horticultural Research Institute insectary following the methods described in Wari et al. (2020).

\section{Insecticides and fungicides}


Eighteen insecticides and five fungicides registered in the management of tomato pests and diseases in Ibaraki Prefecture were used in this study. Pesticides were prepared as per the agriculturally recommended dosage for bioassays and field applications rates (See Table S1).

\section{Bioassays}

Nesidiocoris tenuis toxicity assays

Mortality rates of $N$. tenuis nymph and adult assays and lethal dosage toxicity assays were performed essentially as described in Wari et al. (2021). In brief, 15-20 N. tenuis nymphs and adults were offered to artemia cysts contaminated with pesticides and incubated under laboratory conditions of $25 \pm 1^{\circ} \mathrm{C}$, $65 \pm 10 \% \mathrm{RH}$ and 16:8 L:D photoperiod. Seventy-two hours later, dead or alive individuals were assessed by touching them with a brush. No movement was considered dead. The mortality rate for each pesticide was corrected using Abbotts formula (Abbott, 1925). Each insecticide treatment had three replicates. Insecticides mainly registered for $B$. tabaci control in tomato production (neonicotinoids, spinosyns, avermectins and milbemycins, pyridine azomethine derivatives and diamides) were further tested for their $\mathrm{LD}_{50}$ against $N$. tenuis nymphs and adults. Mortality rates were calculated from the series of concentrations and lethal dose determined.

Furthermore, potted assays were performed in semi-greenhouse conditions to mimic the movement of $N$. tenuis from banker plants to tomato plants after having been sprayed with pesticides. First, $N$. tenuis were released onto the banker plants ( $V$. terena cv. Tapian, $S$. indicum and $C$. spinosa) that had been cultivated in the greenhouse. Six weeks later, 6-week-old tomato seedlings were sprayed with pesticides and placed on a mesh bench adjacent to banker plants with $N$. tenuis. Violet-LEDs were then set behind the tomato seedlings to attract $N$. tenuis adults from the banker plants to the tomato seedlings. The number of $N$. tenuis adults (not dead) on tomato seedlings reated with different pesticides and at different concentrations were quantified after 3, 6, 10 and 18 days. After every count at 3,6 and 10 days, tomato seedlings were randomly repositioned from their previous position to allow random movement of $N$. tenuis from the banker plants when attracted to the violet-LEDs. Six tomato seedlings were used as replicates for each pesticide.

Bemisia tabaci adult and nymph toxicity assays

Mortality rates of $B$. tabaci nymphs and adult assays were performed as described in Wari et al. (2020). In brief, 15-20 B. tabaciadults were subjected to Capsicum annuum leaves leaf-dipped into insecticide solutions. Each insecticide treatment had four biological replicates. After 72 hours, living or dead adults were tallied, and mortality rate computed using Abbott's formula (Abbott, 1925). Bemisia tabaci nymphs, on the other hand, was assayed on Phaseolus vulgaris plants. Bemisia tabaci adults were first allowed to lay eggs on the underside of the $P$. vulgaris leaves, and once the eggs reached $2^{\text {nd }}$ instar stage, bioassays were performed. Phaseolus vulgaris leaves containing the B. tabaci $2^{\text {nd }}$ instar nymphs were leaf-dipped, air dried then placed in the incubator under laboratory conditions. After 6 to 7 days, $2^{\text {nd }}$ instar nymphs 
progressing to $4^{\text {th }}$ instar nymphs were quantified, and mortality rate computed using Abbott's formula (Abbott, 1925). Two broad leaves of the 2-week-old P. vulgaris plants halved by the mid-vein yielding four halves were used as four replicates.

\section{Field tests; integrating $N$. tenuis with biological control components and selective pesticides}

\section{Experimental treatment}

Field test treatments in this study are as follows; (i) IPM treatment, (ii) semi-IPM treatment, (iii) banker plants treatment, (iv) positive control, and a (iv) negative control treatment. IPM treatment included the integration of $N$. tenuis with banker plants, violet-LEDs and selective pesticides. Semi-IPM treatment involved $N$. tenuis with banker plants and violet-LEDs but without selective pesticides. Banker plants treatment was set up as a negative control treatment to IPM and semi-IPM treatments to assess and compare the movement of $N$. tenuis from banker plants to tomato plants. Banker plants treatment included $N$. tenuis and banker plants only but without violet-LEDs and selective pesticides. Positive control treatment consisted of synthetic pesticides, both selective and non-selective, that were sprayed routinely to control $B$. tabaci populations (See Table S2 for pesticide type and date of pesticide application). To verify the role of $N$. tenuis and the biological control components with selective pesticides against $B$. tabaci densities, a negative control treatment with no pest control means but $B$. tabaci only was included.

\section{Greenhouse preparations and experiment settings}

Field studies were performed in two consecutive years, 2019 and 2020. The experiments were conducted in the Ibaraki Horticultural Research Institute inside $10 \mathrm{~m}$ by $5 \mathrm{~m}$ vinyl pipe greenhouses. Greenhouse preparations, tomato seed sawing and transplantation are as described in Wari et al. (2020) and Saito et al. (2021). In brief, three weeks after transplanting tomato seedling and banker plants, N. tenuis and $B$. tabaci were released. Nesidiocoris tenuis nymphs and adults were released directly onto the banker plants (and not onto tomato seedlings) for IMP, semi-IPM and banker plants treatments at a rate of 0.5 individual per tomato seedling while $B$. tabaci adults were randomly released onto tomato seedlings in all treatments at a rate of 1 individual per tomato seedling. Nesidiocoris tenuis and $B$. tabaci survey started four weeks after the $N$. tenuis and $B$. tabaci were released. Pesticide type and application schedule for positive control treatment and IPM treatment greenhouse are as shown in Table S2 and S3, respectively. Only selected pesticides that showed moderate to no toxic effect on $N$. tenuis were selected and applied in the IPM treatment. Pesticide application in positive control treatment included all synthetic pesticides, irrespective of selective or non-selective, were applied on a weekly basis to control $B$. tabaci populations.

\section{Sampling and quantification of test subjects}

Quantification of $N$. tenuis individuals on tomato and banker plants are essentially as discussed in Saito et al. (2021). In brief, $N$. tenuis nymphs and adults on tomato plants were quantified by visually scanning each tomato plant. Nesidiocoris tenuis nymphs and adults on the underside and topside of tomato 
leaves, as well as on the flower stalks and shoots, were counted and recorded. To minimize errors in quantifying $N$. tenuis on tomato plants, as adults are prone to disperse when disturbed, disturbance of tomato plants was minimized. Furthermore, the entire counting was performed by one person for consistency and to keep track of the $N$. tenuis movement. To assess the relocation of $N$. tenuis individuals, tomato plants in each greenhouse were clustered in four zones. Nesidiocoris tenuis nymph and adult counts for each of the zones (10 12 tomato plants per zone) were pooled together and the average computed to represent each zone. To determine the population densities of $N$. tenuis on tomato plants in each treatment throughout the study period, $N$. tenuis (both nymph and adult) counts from all tomato plants (40 48 tomato plants per greenhouse) were pooled together and the average calculated to represent the number of $N$. tenuis per tomato plant. The averages for each sampled week (among zones and all plants in each treatment) were treated as replicates for each treatment per annual study. Nesidiocoris tenuis on the banker plants was quantified by placing a $40 \mathrm{~cm}$ by $20 \mathrm{~cm}$ white bath container 10-15 cm beneath the banker plants. The banker plants were then taped ten times. Nesidiocoris tenuis nymphs and adults that fell onto the white bath container were quantified and recorded as representative of the respective banker plants in a treatment and of the particular sampling period. Sampling of $N$. tenuis on banker plants were performed separately for each of the banker plants i.e. verbena, cleome and sesame.

Bemisa tabaci eggs, nymphs, and adults were quantified following the methods described by Wari et al. (2020) and Saito et al. (2021). In brief, twenty leaves per treatment were sampled every week. Eggs and nymphs (including $1^{\text {st }}, 2^{\text {nd }}, 3^{\text {rd }}$, and $4^{\text {th }}$ instar nymphs) on the underside of the tomato leaves were counted using a Leica S6E stereo microscope mounted with a Leica KL300 LED illumination. Bemisia tabaci egg and nymph counts for the twenty leaves were pooled together and the average calculated to designate the $B$. tabaci egg and nymph counts per tomato leaf in a given treatment. The averages for each sampled week were treated as replicates for each treatment per annual study. One $200 \mathrm{~cm}^{2}$ yellow sticky trap (Arysta Lifesciences, Tokyo, Japan) was set in the middle of each treatment and collected after three days to determine B. tabaci adult population. Sticky traps setting and collection (together with leaves) were performed on a weekly basis for 13 consecutive weeks. After leaf and sticky trap sampling, pesticides were applied in the positive control and IPM treatment as per the application schedule in Table S2 and S3.

\section{Statistical analyses}

Nesidiocoris tenuis (nymphs and adults) and B. tabaci (eggs, nymphs and adults separately) counts were tested for normality (Shapiro-Wilk test and Lilliefors test) and homogeneity (Bartlett's Test) using opensource software OpenStat (http://openstat.info/OpenStatMain.htm). The total number of N. tenuis (nymphs and adults) and $B$. tabaci eggs, nymphs and adults were then transformed logarithmically using ' $x+1$ ' to meet the assumptions of analysis of variance (ANOVA). The effects of 'treatments (banker plants, semi-IPM and IPM)' and 'sampling interval (weeks)' factors and their interaction on the densities of $N$. tenuis on tomato, as well as the effect of banker plants on the abundance of $N$. tenuis on tomato plants were analyzed using repeated-measures ANOVA. Similarly, the effect of N. tenuis on B. tabaci egg, 
nymph and adult densities was analyzed using a repeated-measures ANOVA model with treatment and sampling interval considered as fixed factors. Nesidiocoris tenuis distribution among the zones in the greenhouses between the banker plants, semi-IPM and IPM were analyzed using contingency chi-square test for two-way tables to test the relationship between treatments and zones. Furthermore, standard deviations (SD) were calculated from the mean of pooled data (40 48 tomato plants per greenhouse for $N$. tenuis counts per treatment, 10 12 tomato plants per zone for $N$. tenuis counts per zone, 20 tomato plant leaves per treatment for $B$. tabaci eggs and nymphs, and one $200 \mathrm{~cm}^{2}$ yellow sticky trap per treatment for $B$. tabaci adults) per sampled week from two annual studies to represent the differences between the years.

\section{Results}

\section{Pesticide toxicity against N. tenuis}

To determine if insecticides registered for $B$. tabaci management in tomato production under greenhouse conditions can be toxic or harmless to $N$. tenuis, in-vitro toxicity assays were performed. Eight insecticides were tested against nymphs and adults of $N$. tenuis and $B$. tabaci. Results showed that dinotefuran, spinetram and abamectin at the agriculturally recommended dose, were moderately toxic to very toxic to nymphs and adults of both $N$. tenuis and $B$. tabaci with over 50 to $100 \%$ mortality rates (Table 1). Milbemectin, lepimectin, pyrifluquinazon and cyantraniliprole were toxic to $B$. tabaci nymphs and adults with over $70 \%$ mortality rate, however, less toxic to nymphs and adults of $N$. tenuis with mortality rates less than $50 \%$ (Table 1 ). Flonicamid was observed to be less toxic to nymphs and adults of both $N$. tenuis and B. tabaci (Table 1).

To further substantiate these results, median lethal dose $\left(\mathrm{LD}_{50}\right)$ was determined for each insecticide. Results showed that $\mathrm{LD}_{50}$ for dinotefuran (21 and 1000 folds for nymphs and adults respectively), acetamiprid (1.5 and 25 folds for nymphs and adults respectively), spinosyns ( 1.6 and 26 folds for nymphs and adults respectively), abamectin ( 9 and 66 folds for nymphs and adults respectively) and emamectin benzoate ( 5 and 9 folds for nymphs and adults respectively) were less than the agriculturally recommended dose (Table 2 ) affirming the high toxicity against $N$. tenuis nymphs and adults as shown in Table 1 (and Table 3 for acetamiprid and emamectin benzoate). LD 50 for milbemectin (293 and 201 folds for nymphs and adults respectively), pyrifluquinazon (672 and 1110 folds for nymphs and adults respectively) and cyantraniliprle (6854 and 922 folds for nymphs and adults respectively) higher than the agriculturally recommended dose (Table 2 ) affirming their reduced toxicity against $N$. tenuis nymphs and adults as shown in Table 1. Lepimectin, on the other hand, showed $L D_{50}$ values 4 folds less than the agriculturally recommended dose against $N$. tenuis nymphs but 3.5 folds higher than the agriculturally recommended dose against the adults, inconsistent with the toxicity assays shown in Table 1. Furthermore, pot-assays in semi-field conditions also revealed that non-to-fewer $N$. tenuis adults ( 0 to $0.2 \pm 0.5$ per seedling) preferred tomato seedlings sprayed with dinotefuran, spinetoram and milbemectin relative to abamectin, lepimectin, pyrifluquinazon, cyantraniliprole and flonicamid (Table S4). These 
results suggest that dinotefuran and spinetoram are toxic to $N$. tenuis nymphs and adults and therefore, incompatible to be integrated with $N$. tenuis. Abamectin, milbemectin and lepimectin showed inconsistent but moderate toxic effects in the in-vitro assays as well as potted-assays against $N$. tenuis. Furthermore, abamectin, milbemectin, lepimectin and emamectin benzoate were observed to be toxic to $B$. tabaci. Therefore, these insecticides can be used as $N$. tenuis suppressants when $N$. tenuis densities are beyond threshold limits at the same time, control $B$. tabaci. Pyrifluquinazon and cyantraniliprole showed toxicity with high mortality rates against $B$. tabaci but less toxic to $N$. tenuis. Thus, pyrifluquinazon and cyantraniliprole can be good candidates to be integrated with $N$. tenuis as selective pesticides.

Insecticides and fungicides registered for managing pests and diseases other than $B$. tabaci were also tested for their toxicity against $N$. tenuis. Results showed that acetamiprid and emamectin benzoate mostly used for managing aphids and leaf miners, respectively, and fluxametamide for multiple pests, were highly toxic to nymphs and adults of $N$. tenuis with mortality rates over $70 \%$ to $100 \%$ (Table 3 ). Chlorfenapur, registered to control cotton ballworm in tomatoes, was less toxic to $N$. tenuis nymphs (11.1 \pm 7.5$)$ but moderately toxic to the adults $(56.0 \pm 18.1)$ (Table 3$)$. Lufenuron, bifenazate and spirotetramat registered in tomato production for spider mite control, tetraniliprole for managing thrips, flurometokin for other related pests and acetylated glyceride, a recently registered compound as a repellent and antifeedant of whiteflies, all have showed to be less toxic to both the nymphs and adults of $N$. tenuis (Table 3). Furthermore, pot-assays revealed that $N$. tenuis adults were observed on tomato seedlings sprayed with emamectin benzoate, chlorfenapyr, lufenuron, bifenazate, spirotetramat, tetraniliprole and furometokin three days post-treatment and increased as the survey continued. Brief occurrence of $N$. tenuis adults was noted six days post treatment for fluxametamide and 10 days post treatment for acetamiprid but no $N$. tenuis adults were detected thereafter (Table S4). Fungicides registered for powdery mildew management in tomato produced under greenhouse conditions were also tested for their toxicity on $\mathrm{N}$. tenuis nymphs and adults in-vitro and in potted-assays. Results showed that the five fungicides were not toxic to the nymphs and adults of $N$. tenuis in-vitro (Table 3 ) and in pottedassay (Table S6). These results suggest that insecticides registered for pest control other than B. tabaci, acetamiprid and fluxametamide are incompatible with $N$. tenuis while emamectin benzoate and chlorfenapur can only be options when leaf miners and cotton ballworm are beyond economic threshold limits. Fungicides registered for powdery mildew control can be used in conjunction with $N$. tenuis when powdery mildew and other related fungal disease incidences are detected.

\section{Relocating N. tenuis on tomato plants using violet-LEDs}

To determine if $N$. tenuis can successfully establish on tomato plants when attracted by violet-light (in the form of violet-LEDs) from the banker plants, the movement of $N$. tenuis was assessed weekly. According to Uehara et al. (2019), N. tenuis become active during the dusk, therefore, violet-LEDS were connected to an automatic switch that switched on the violet-LEDS from 5:00 pm and off at 8:00 pm, to coincide with dusk. The greenhouse was divided into four zones, zone 1 adjacent to banker plants and zone 4 by the violet-LEDs. The movement of $N$. tenuis from banker plants towards the violet-LEDs was assessed by quantifying $N$. tenuis individuals on each tomato plant. The number of $N$. tenuis individuals on each 
tomato plants in a zone is summed and showed as percentage, as shown in Fig. 1 (nymphs and adults combined), Fig. S1A, B and C (adults only) and Fig. S1D, E and F (nymphs only). Results showed that $N$. tenuis relocated from banker plants and onto tomato plants and scattered among tomato plants in all zones in semi-IPM and IPM treatments with violet-LEDs. On the other hand, $N$. tenuis in banker plants treatment (where no violet-LEDs were installed) were mainly situated in zone 1 in the first two weeks of the survey. This is evident as $N$. tenuis counts were highly significantly different $(p=<0.001)$ between the violet-LED equipped treatments (IPM and semi-IPM) and no violet-LED equipped treatment (banker plants) as well as between the zones from week one of the survey until week nine (Table 4). Nesidiocoris tenuis individuals detected on tomato plants in the three treatments were mainly of the adults (Fig. S1A, B and C). Nesidiocoris tenuis nymphs were detected 8 weeks later from the time they were released in banker plants treatment, 6 weeks later for semi-IPM treatment and 5 weeks later in the IPM treatment, respectively (Fig. S1D, E and F). Furthermore, in the banker plants only treatment, $N$. tenuis distribution in all four zones became apparent in the tenth week from the start of the survey $(p=>0.05)$ (Table 4) (Fig. 1). These observations suggest that violet-lights are essential and effective in accelerating the relocation of $N$. tenuis from banker plants and successfully establishing on tomato plants, where pests are usually found.

\section{Densities of $N$. tenuis on tomato and banker plants}

To assess how the $N$. tenuis population established and shifted on tomato plants after relocating from banker plants aided by violet-LEDs, the number of $N$. tenuis individuals (nymphs and adults included) per tomato plant was determined. The population trends of $N$. tenuis on tomato plants are shown in Fig. 2A. Gradual increase in the number of $N$. tenuis in semi-IPM and IPM treatment relative to the $N$. tenuis trend in banker plants treatment was observed. All the same, a significant increase in $N$. tenuis during postrelease was observed on tomato plants in the three treatments. However, the onset of the increase was significantly earlier in semi-IPM and IPM treatment than in banker plants treatment, leading to the significant interaction in the sampling interval $(p=<0.001)$ (Table 5). The significant increase in the number of $N$. tenuis per tomato plant in semi-IPM and IPM rose until week 7 of the survey until the population trends of $N$. tenuis in IPM dropped briefly. The drop can be attributed to the application of pyrifluquinazon (Table S3). Nesidiocoris tenuis densities in semi-IPM progressively increased, while $N$. tenuis densities in banker plants treatments commenced to gradually decline while $N$. tenuis numbers in IPM began to steadily rise, leading to the highly significant interaction between the three treatments $(P<$ $0.001)$.

Nesidiocoris tenuis on banker plants (sum of $N$. tenuis nymphs and adults in the three banker plants; verbena, sesame and cleome) gradually increased as the study progressed, reaching maximum peak for banker plants only $(328.0 \pm 63.5)$ and semi-IPM $(324.0 \pm 38.4)$ treatments at the eleventh week from the time they were released onto the banker plants (Fig. 2B). The $N$. tenuis on the banker plants in IPM treatment however, reached its maximum peak $(410.5 \pm 35.0)$ one week ahead of banker plants only and semi-IPM treatments (Fig. 2B). Different cultivation practices did not have any effect on the $N$. tenuis densities on the three banker plants combined $(p=0.821)$ (Table 5$)$. The sum of the three banker plants 
yielded increased number of $N$. tenuis (nymphs and adults), however, $N$. tenuis densities on individual banker plants showed that $N$. tenuis preferred sesame and cleome, rather than verbena (Fig. S2).

The effect of violet-LEDs was evident as the densities of $N$. tenuis on banker plants in semi-IPM were not significantly different from those on the tomato plants $(p=0.052)$ (Table 5$)$ compared to the banker plants treatment, in which $N$. tenuis densities were higher in banker plants but very few moving to tomato plants $(p=0.026)$ (Table 5, Fig. 1 and Fig 2A). On the other hand, $N$. tenuis densities on banker plants in IPM treatment were significantly different to those on the tomato plants $(p=<0.001)$ (Table 5). The differences observed here as compared to semi-IPM can be due to the selective pesticides applied in IPM treatment (Table S3), as a result leading to a significant interaction in the sampling interval $(p=<0.001)$ (Table 5).

Integrated effect of $N$. tenuis, biological control components and selective pesticides on different growth stages of $B$. tabaci

To determine if the augmentative impact of natural enemy, banker plants, violet-lights (violet-LEDs), and selective pesticides (IPM treatment) on the densities of $B$. tabaci, different growth stages of $B$. tabaci eggs, nymphs and adults were surveyed. To validate the effect of $N$. tenuis integrated with biological control components (i.e., IPM treatment), a positive control treatment with vigorous pesticides usage and a negative control treatment with no control means to control $B$. tabaci under greenhouse conditions were included. There were significant differences in the augmentative effect of $N$. tenuis integrated with banker plants, violet-LEDs and selective pesticides (IPM treatment) on $B$. tabaci compared to semi-IPM treatment (N. tenuis+banker plants+violet-LEDs) (nymphs: $p=0.036$ and adults: $p=0.022$ ), banker plants treatment (N. tenuistbanker plants) (eggs: $p=0.049$; nymphs: $p=0.040$ and adults: $p=0.002$ ) and negative control treatment (no pest control means) (eggs: $p=0.007$; nymphs: $p=0.001$ and adults: $p=0.019$ ) (Table 6). On the other hand, no significant difference was observed between the IPM treatment and positive control (conventional greenhouse) on $B$. tabacieggs $(p=0.643)$, nymphs $(p=0.857)$ and adults $(p=0.410)$. The effects and interaction between the treatments and sampling intervals are reflective of the $B$. tabaci population trends shown in Fig. 3. These results demonstrate that $N$. tenuis when augmented with biological components such as banker plants to promote breeding and proliferation; violet-lights to enhance relocation from banker plants to tomato plants; and selective pesticides in managing $B$. tabaci growth stages that cannot be preyed on by the natural enemy, collectively can suppress $B$. tabaci incidences. However, further studies on the augmentative effect of $N$. tenuis, biological components, and selective pesticides on consecutive annual studies and in large scale systems is needed to categorically substantiate these results.

\section{Discussion}

Nesidiocoris tenuis is both a beneficial natural enemy and a pest too, a foe and a friend, or as annotated by Ferguson et al (2020), a Jekyll and Hyde. In Japan, $N$. tenuis has been effectively integrated into the management of several greenhouse pests such as whiteflies and thrips on tomato plants (Nakano et al. 
2016; Yano et al. 2020). While feeding damage on tomato plants is still unknown, NARO (2019) recommends that the initial number of $N$. tenuis to be released at the start of tomato cultivation at a rate of one $N$. tenuis individual per two tomato plants. Calvo et al. (2009) in their findings recommended one $N$. tenuis individual per tomato plant. According to two separate studies at two geographically different localities, it would be safe to assume that $N$. tenuis at a rate of 0.5 to 1 individual per tomato plant is enough to not cause any feeding damage that may result in significant economic losses. However, in time, $N$. tenuis can breed, proliferate and increase in numbers exceeding the recommended rates. And when prey becomes scarce, $N$. tenuis may tend to plant feed, resulting in damages to plants. To elucidate this dilemma, banker plants have been suggested. Banker plants are known for their role in promoting natural enemies to densities beyond threshold limits. With banker plants as the source base for natural enemies, and when cultivated together with crops, natural enemies can migrate to crops where pests are situated and begin pest feeding. Hypothetically, this is workable and can be an economically and environmentally viable solution for pest control. Nakano et al. (2016) in their three-year study showed that $N$. tenuis integrated with banker plants (Verbena $\times$ hybrida cv. Tapian) successfully colonized the tomato, however, the impact of $N$. tenuis on the population densities of $B$. tabaci could only be realized at the end of the cultivation period. They further showed that integrating $N$. tenuis with banker plants and selective pesticides somewhat impacted the rates of TYLCV, a viral disease vectored by $B$. tabaci, compared to conventional plots. They concluded that combining $N$. tenuis and banker plants can be effective in managing $B$, tabaci populations and as a result, inhibiting the spread of TYLCV. On the other hand, Uehara et al. (2019) postulated that supplementing $N$. tenuis with banker plants is innovative however, reestablishing $N$. tenuis on tomato plants can be difficult given that $N$. tenuis prefers banker plants more than the tomato plants. Similar observations were reported in our previous study (Saito et al. 2021). Uehara et al. (2019) further investigated different light spectrums as an attraction mechanism. They showed in laboratory and greenhouse conditions that while $N$. tenuis preferred banker plants more, when supplemented with violet-lights, $N$. tenuis relocated from banker plants and became evenly dispersed on tomato plants.

Expounding on Nakano et al. (2016) and Uehara et al. (2019) studies, we tested under greenhouse conditions the impact of integrating $N$. tenuis, banker plants, violet-lights and selective pesticides on the population densities of $B$. tabaci. Results showed that population densities of different growth stages of B. tabaci were no different to that of the chemical control treatment. Additionally, we also surveyed the occurrence of powdery mildew and TYLCV incidences during the study. Reduced powdery mildew and TYLCV incidences were observed in the IPM treatment compared to other treatments (Fig. S3A and B). Furthermore, all tomato plants in banker plants treatment showed necrotic rings (as result of $N$. tenuis feeding) nine weeks from the start of the study. In contrast, 50 per cent and less than 30 per cent in semiIPM and IPM treatment, respectively, was observed 10 weeks from the start of the study (Fig. S3C). The zero occurrence of powdery mildew incidences in IPM and positive control greenhouses is the direct impact of fungicides sprayed sparingly during the study (Table S3 and Fig. 3A). Reduced but not complete inhibition of TYLCV incidences is attributable to the integrated impact of $N$. tenuis, acetylated glyceride and other selective pesticides in managing the densities of $B$. tabaci spreading the virus (Table 
S3 and Fig. 3B). Furthermore, the decreased feeding damage on tomato plants (Fig. S3C) by N. tenuis can be associated with the selective pesticides (Table S3) maintaining low densities of $N$. tenuis on tomato plants (Fig. 2). Collectively, integrating natural enemies may broaden its efficacy to the target pest and the related pest and diseases that co-occur during the cultivation period.

As a zoophytophagous mirid bug, $N$. tenuis sustains itself by feeding on animals, and is also known to feed on plants or crops resulting in crop damage and yield losses (Arnó et al. 2010; Pérez-Hedo \& Urbaneja, 2016; Sanchez, 2009; Sanchez \& Lacasa, 2008). Even then, N. tenuis phytophagous behavior have been shown to induce herbivore-induced plant volatiles (HIPVs) which can help modulate pest and natural enemy locations, attract beneficial insects and deter pests (Bouagga et al. 2018; Pérez-Hedo et al. 2018). In the Mediterranean Basin, management of greenhouse pests compensates the feeding damage caused by N. tenuis (Bhatt \& Patel, 2018; Pérez-Hedo et al. 2017). On the contrary, plant feeding damage caused by $N$. tenuis is more severe than the benefits it brings as a natural enemy, thus it has been considered a pest in the south of France (Trottin-Caudalet al 2006; Trottin-Caudal \& Millot, 1997) and recently in Belgium and the Netherlands (Moerkens et al. 2020). Nesidiocoris tenuis being a beneficial natural enemy and a pest is still a controversy. However, the beneficial natural enemy to greenhouse pests is still practicable if augmented with biological control components and selective pesticides. Pesticides have always been the first line of defense particularly in large scale farming as profits always outweigh the running costs of the pesticides, let alone the many adverse effects on the environment, development of pesticide resistance and their impacts on beneficial insects. Nevertheless, not all pesticides are toxic to all kinds of insects. Adoption of newly developed insecticides that are selective (harmful to pests but nontoxic to beneficial insects) and their role in improving IPM systems have been widely reported (Orr, 2009). The use of selective pesticides is perhaps the most powerful tool by which pesticide use decisions can be modified to favor natural enemies (Hull and Beers, 1985), and the one most readily available to growers (Ruberson et al. 1998). Selecting the best insecticides for pest management that have minimal impacts on the beneficials can be challenging. If appropriately integrated with biological components and carefully tested and selected pesticides, $N$. tenuis densities can be maintained at acceptable threshold limits to control greenhouse pests and not cause economic damage on plants. While this is not an authentic means of pest control, and given that pest problems always evolve in time, additional research is regularly needed to perfect the $N$. tenuis integration into IPM programs.

Biological control and its role in pest management dates back to ancient times. Over the past couple of decades, biological control has flourished in a flush of optimism for a "silver bullet" (a simple and seemingly magical solution to a complicated problem) (Cock et al. 2016). These phenomena have prompted many to question if biological control is still a necessary, safe, and effective means of pest control (McEvoy and Coombs 2000). And then, there is the augmentation of biological control in IPM systems. Although not innovative in pest management technologies, there are always constraints to a successful augmentation of biological control and IPM. Besides, there are many varieties of options and prospects offered by natural enemies and the technology available to manage a vast and ever-increasing pest problems. Furthermore, societies' concern for environmental and human safety, pollution, resistance to pesticides, and the high running cost of pesticide use suggests the need for an effective but safe and 
cost-efficient means. Biological control augmented in IPM systems is one such instance that is already in motion but in need for fine-tuning, implementation and exposure to be adopted for general use.

Pesticides, on the other hand, are an integral arm of IPM. While pesticides may have negative impacts on the environment and humans alike, pesticides are here to stay, as they play a major role in pest control. As such, a more environmentally and ecologically sound approach in using pesticides therefore, is a prerequisite and promotion of selective or guided pesticide use is a means forward into the future, if IPM system are to work effectively. Nesidiocoris tenuis, has been a success story in managing greenhouse pests across many countries. Although, it may be considered a controversial natural enemy in Europe, there are means by which its negative impact on plants can be corrected. Case in point, integrating $N$. tenuis with biological control components and properly supplemented with selective or guided pesticides, as shown in this study, can minimize the negative effects of $N$. tenuis, improve pest control, be safer to the environment, and generally a step forward in IPM advancement.

\section{Declarations}

\section{Acknowledgments}

The authors are grateful for the support by Ibaraki Prefectural Government strategizing projects aimed at easing pest and disease outbreaks in tomato farms in Ibaraki Prefecture, Japan. The authors are also grateful to Ibaraki Horticultural Institute technical and casual staff for their technical support and Professor Craig Sower (Emeritus Professor of English, Shujitsu University, Okayama, Japan) for proof reading and English editing of this manuscript.

\section{Funding}

This research received no external funding.

\section{Compliance with ethical standards}

\section{Conflict of interest}

The authors declare no conflict of interests.

\section{Ethics approval}

Not applicable

\section{Consent to participate}

Not applicable

\section{Consent for publication}

Not applicable 


\section{Author Contributions}

Conceptualization: DW, MT and TO; Methodology: DW, TS, MT, RO, TM, TT, MS and TO; Formal analysis and investigation: DW, TS, RO and TM; Writing - original draft preparation: DW; Writing - review and editing: DW, TS, MT, RO, TM, TT, MS and TO; Funding acquisition: MT, TM and TO; Resources: TT for the N. tenuis and banker plants, MS for LEDs.

\section{References}

Abbott, WS. A method of computing the effectiveness of insecticides (1925) J Econ Entomol 18:265267. https://doi.org/10.1093/jee/18.2.265a

Arno J, Gabarra R, Liu TX, Simmons AM, Gerling D (2010) Natural enemies of Bemisia tabaci: predators and parasitoids. In: Stansly PA, Naranjo SE (eds) Bemisia bionomics and management of a global pest. Springer, Dordrecht, pp 385-421

Barzman M, Bàrberi P, Birch NE, Boonekamp P, Dachbrodt-Saaydeh S, Graf B, Hommel B, Jensen JE, Kiss J, Kudsk P, Lamichhane JR, Messéan A, Moonen AC, Ratnadass A, Ricci P, Sarah JL, Sattin M (2015) Eight principles of integrated pest management. Agronomy for Sustainable Development 35:1199-1215.

Bhatt N, Patel MV (2018) Tomato bug, Nesidiocoris tenuis (Reuter): A zoophytophagous insect. J Entomol Zool 6:1550-1556. https://doi.org/10.1007/s10526-012-9486-7

Biondi A, Zappalà L, Di Mauro A, Tropea Garzia G, Russo A, Desneux N, Siscaro G (2016) Can alternative host plant and prey affect phytophagy and biological control by the zoophytophagous mirid Nesidiocoris tenuis? Biocontrol 61:79-90. https://doi.org/10.1007/s10526-015-9700-5

Bouagga S, Urbaneja A, Rambla JL, Flors V, Granell A, Jaques JA, Pérez-Hedo M (2018) Zoophytophagous mirids provide pest control by inducing direct defenses, antixenosis and attraction to parasitoids in sweet pepper plants. Pest Manag Sci 74:1286-1296. https://doi.org/10.1002/ps.4838

Calvo FJ, Bolckmans K, Stansly PA, Urbaneja A (2009) Predation by Nesidiocoris tenuis on Bemisia tabaci and injury to tomato. Biocontrol 54:237-246. https://doi.org/10.1007/s10526-008-9164-y

Calvo FJ, Lorente MJ, Stansly PA, Belda JE (2012) Preplant release of Nesidiocoris tenuis and supplementary tactics for control of Tuta absoluta and Bemisa tabaci in greenhouse tomato. Entomol Exp Appl 143:111-119. https://doi.org/10.1111/j.1570-7458.2012.01238.x

Calvo FJ, Torres-Ruiz A, Velázquez-González JC, Rodríguez-Leyva E, Lomeli-Flores JR (2016) Evaluation of Dicyphus hesperus for biological control of sweet potato whitefly and potato psyllid on greenhouse tomato. Biocontrol 61:415-424. https://doi.org/10.1007/s10526-016-9719-2

Cock MJ, Murphy ST, Kairo MT, Thompson E, Murphy RJ, Francis AW (2016) Trends in the classical biological control of insect pests by insects: an update of the BIOCAT database. Biocontrol 61:349-363. 
Ferguson KB, Visser S, Dalíková M, Provazníková I, Urbaneja A, Pérez-Hedo M, Marec F, Werren JH, Zwaan BJ, Pannebakker BA, Verhulst EC (2020) Jekyll or Hyde? The genome (and more) of Nesidiocoris tenuis, a zoophytophagous predatory bug that is both a biological control agent and a pest. Insect Mol Biol. In press https://doi.org/10.1111/imb.12688.

Garantonakis N, Pappas M, Varikou K, Skiada V, Broufas G, Kavroulakis N, Papadopoulou K (2018) Tomato inoculation with the endophytic strain Fusarium solani $\mathrm{K}$ results in reduced feeding damage by the zoophytophagous predator Nesidiocoris tenuis. Front Ecol Evol 6:1-7.

https://doi.org/10.3389/fevo.2018.00126

Gentz MC, Murdoch G, King GF (2010) Tandem use of selective insecticides and natural enemies for effective, reduced-risk pest management. Biol Control 52:208-215.

https://doi.org/10.1016/j.biocontrol.2009.07.012.

Ghoneim K (2014) Predatory Insects and Arachnids as Potential Biological Control Agents against the Invasive Tomato Leaf Miner, Tuta absoluta Meyrick (Lepidoptera: Gelechiidae): In Perspective and Prospective. J Entomol Zool 2: 52-71.

Huang N, Enkegaard A, Osborne LS, Ramakers PMJ, Messelink GJ, Pijnakker J and Murphy G (2011) The Banker Plant Method in Biological Control, CRC Crit Rev Plant Sci, 30:3, 259-278, https://doi.org/10.1080/07352689.2011.572055

Hull LA, Beers EH (1985) Ecological selectivity: Modifying chemical control practices to preserve natural enemies. In: Hoy, M.A. and Herzog, D.C. (eds), Biological Control in Agricultural IPM Systems. Academic Press, Orlando, FL, pp. 103-122.

McEvoy PB, Coombs EM (2000) Why things bite back: unintended consequences of biological weed control. In: Follett PA, Duan JJ (eds) Nontarget effects of biological control. Kluwer Academic Publishers, Boston, pp 167-194

Moerkens R, Pekas A, Bellinkx S, Hanssen I, Huysmans M, Bosmans L, Wackers F (2020) Nesidiocoris tenuis as a pest in Northwest Europe: Intervention threshold and influence of Pepino mosaic virus. J Appl Entomol 144:566-577. https://doi.org/10.1111/jen.12789

Nakaishi K, Fukui Y, Arakawa R (2011) Reproduction of Nesidiocoris tenuis (Reuter) on Sesame. Jpn J Appl Entomol Zool 55:199-205. https://doi.org/10.1303/jjaez.2011.199 (in japanese with English abstract)

Nakano R, Tsuchida Y, Doi M, Ishikawa R, Tatara A, Amano Y, Muramatsu Y (2016) Control of Bemisia tabaci (Gennadius) on tomato in greenhouse by a combination of Nesidiocoris tenuis (Reuter) and banker 
plants. Ann Rep Kansai PI Prot 58:65-72 https://doi.org/10.4165/kapps.58.65 (in japanese with English abstract)

NARO (2019) New manual for tomato pest control system that reduces the use of synthetic insecticides. (In Japanese)https://www.naro.affrc.go.jp/publicity_report/publication/files/SIPtomatomanual1904042205s.pdf (24th of August, 2020)

Ogino T, Uehara T, Muraji M, Yamaguchi T, Ichihashi T, Suzuki T, Kainoh Y, Shimoda M (2016) Violet LED light enhances the recruitment of a thrip predator in open fields. Sci Rep 6:32302.

https://doi.org/10.1038/srep32302

Orr D (2009) Biological control and integrated pest management. In: Peshin R, Dhawan A (eds) Integrated pest management: innovation-development process. Springer, Dordrecht, pp 207-239

Owashi Y, Hayashi M, Abe J, Kazuki M (2019) Effects of an alternative diet of Artemia cysts on the development and reproduction of Nesidiocoris tenuis (Hemiptera: Miridae). Appl Entomol Zool. 55: 121127. https://doi.org/10.1007/s13355-019-00660-y

Park YG, Lee JH (2021) UV-LED lights enhance the establishment and biological control efficacy of Nesidiocoris tenuis (Reuter) (Hemiptera: Miridae). PLoS ONE 16(1): e0245165.

https://doi.org/10.1371/journal.pone.0245165

Pérez-Hedo M, Urbaneja A (2015) Prospects for predatory mirid bugs as biocontrol agents of aphids in sweet peppers. J Pest Sci 88:65-73 https://doi.org/10.1007/s10340-014-0587-1

Pérez-Hedo M, Urbaneja A (2016) The zoophytophagous predator Nesidiocoris tenuis: A successful but controversial biocontrol agent in tomato crops. Horowitz, A \& Ishaaya, I., In: Advances in Insect Control and Resistance Management. Cham: Springer International Publishing, pp. 121-138.

Pérez-Hedo M, Suay R, Alonso M, Ruocco M, Giorgini M, Poncet C, Urbaneja A (2017). Resilience and robustness of IPM in protected horticulture in the face of potential invasive pests. Crop Prot 97, 119-127. https://doi.org/10.1016/j.cropro.2016.11.001

Pérez-Hedo M, Rambla JL, Granell A, Urbaneja A (2018) Biological activity and specificity of Miridaeinduced plant volatiles. Biocontrol 63: 203-213. https://doi.org/10.1007/s10526-017-9854-4

Pérez-Hedo M, Riahi C, Urbaneja A (2020) Use of zoophytophagous mirid bugs in horticultural crops: Current challenges and future perspectives. Pest Manag Sci 77:33-42. https://doi.org/10.1002/ps.6043

Ruberson JR, Nemoto H, Hirose Y (1998) Pesticides and conservation of natural enemies in pest management. In: Barbosa, P. (ed), Conservation Biological Control. Academic Press, San Diego, CA, pp. 207-220. 
Saito T, Takagi M, Tezuka T, Ogawara T, Wari D, (2021) Augmenting Nesidiocoris tenuis (Nesidiocoris) with a factitious diet of Artemia cysts to control Bemisia tabaci (Gennadius) on tomato plants under greenhouse conditions. Insects 12:265. https://doi.org/10.3390/insects12030265

Sanchez JA (2008) Zoophytophagy in the plant bug Nesidiocoris tenuis. Agric For Entomol 10:75-80. https://doi.org/10.1111/j.1461-9563.2007.00357.x

Sanchez JA, Lacasa A (2008) Impact of the zoophytophagous plant bug Nesidiocoris tenuis (Heteroptera: Miridae) on tomato yield. J Econ Entomol 101:1864-1870. https://doi.org/10.1603/0022-0493101.6.1864

Sanchez JA (2009) Density thresholds for Nesidiocoris tenuis (Heteroptera: Miridae) in tomato crops. Biol Control 51:493-498. https://doi.org/10.1016/j.bioco ntrol.2009.09.006

Shimoda M, Honda K (2013) Insect reactions to light and its applications to pest management. Appl Entomol Zool 48:413-421. https://doi.org/10.1007/s13355-013-0219-x

Shipp JL, Wang K (2006) Evaluation of Dicyphus hesperus (Heteroptera: Miridae) for biological control of Frankliniella occidentalis (Thysanoptera: Thripidae) on greenhouse tomato. J Econ Entomol 99:414-420 https://doi.org/10.1603/0022-0493-99.2.414.

Trottin-Caudal Y, Millot P (1997) Etude de deux mirides en culture de tomate: Macrolophus caliginosus Wagner et Nesidiocoris (Cyrtopeltis) tenuis Reuter. Infos Paris, 131, 40-44.

Trottin-Caudal Y, Fournier C, Leyre JM, Chabriere C (2006) La tomate sous serre dans le Sud-Est de la France. Protection contre la punaise Nesidiocoris tenuis. Infos Ctifl, 224, 30-35.

Torres JB, Bueno AF (2018) Conservation biological control using selective insecticides - A valuable tool for IPM, Biol Control 126:53-64, https://doi.org/10.1016/j.biocontrol.2018.07.012.

Uehara T, Ogino T, Nakano A, Tezuka T, Yamaguchi T, Kainoh Y, Shimoda M (2019) Violet light is the most effective wavelength for recruiting the predatory bug Nesidiocoris tenuis. Biocontrol 64:139-147. https://doi.org/10.1007/s10526-019-09926-4

Urbaneja A, Montón H, Mollá O (2009) Suitability of the tomato borer Tuta absoluta as prey for Macrolophus caliginosus and Nesidiocoris tenuis. J Appl Entomol 133:292-296.

https://doi.org/10.1111/j.1439-0418.2008.01319.x

Wari D, Okada R, Takagi T, Yaguchi M, Kashima T, Ogawara T (2020) Augmentation and compatibility of Beauveria bassiana with pesticides against different growth stages of Bemisia tabaci (Gennadius); an invitro and field approach. Pest Manag Sci 76:3236-3252; https://doi.org/10.1002/ps.5881

Wari D, Takagi M, Ogawara T (2021) Simplified insecticide toxicity determination method for Nesidiocoris tenuis using contaminated diet. MethodsX, 8:101220. https://doi.org/10.1016/j.mex.2021.101220. 
Yano E, Nakauchi M, Watanabe T, Watanabe H, Hosaka S, Nishimori S, Miura S, Kandori I, Hinomoto N (2020) Life history traits of Nesidiocoris tenuis on Bemisia tabaci and Thrips palmi. Biocontrol 2020,65, 155-164 https://doi.org/10.1007/s10526-019-09979-5

\section{Tables}

Tables 1-6 are available in the Supplementary Files.

\section{Figures}

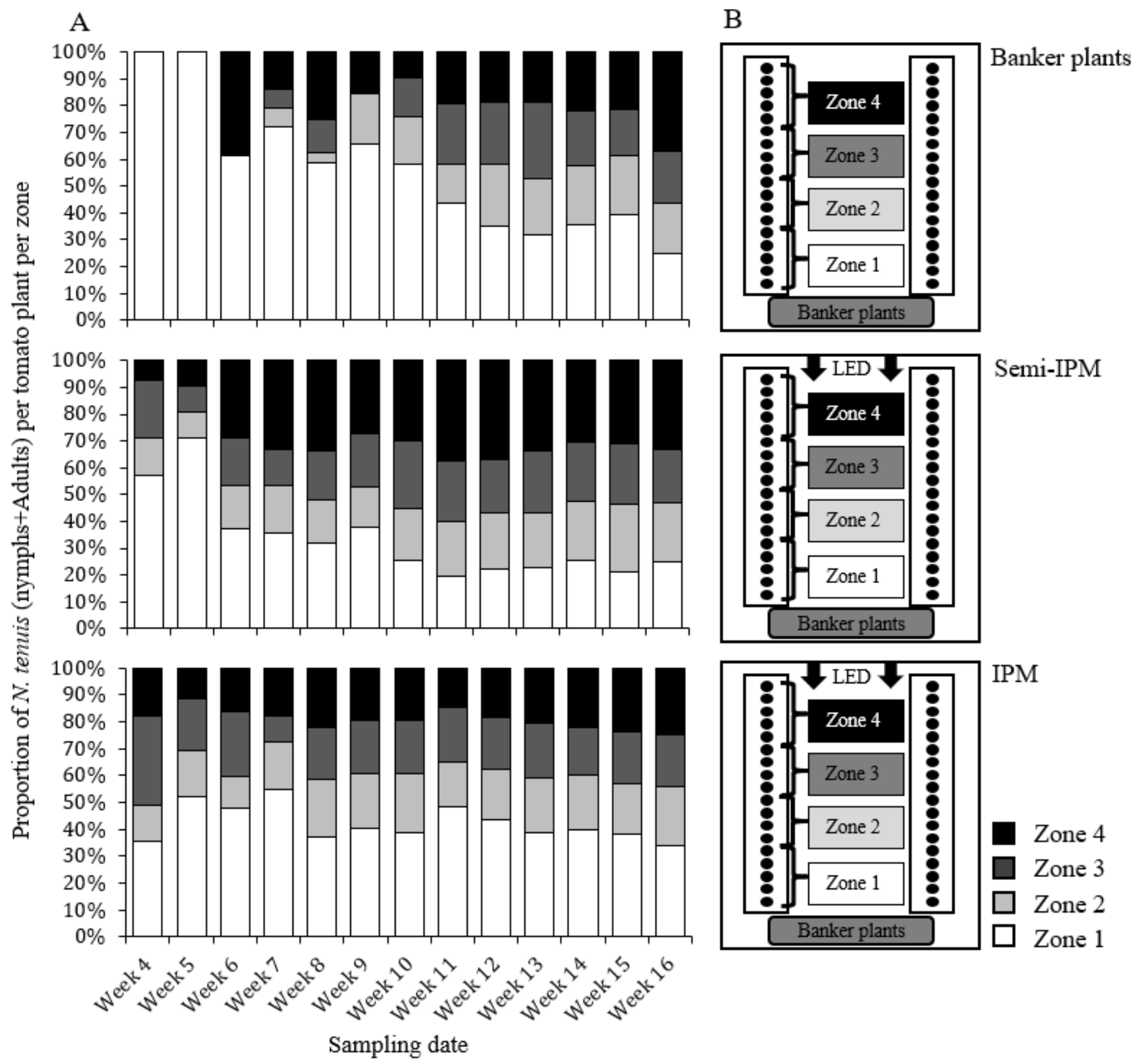


Figure 1

Schematic representation of the dynamics of Nesidiocoris tenuis movement from banker plants to tomato plants. (A) N. tenuis (inclusive of adults and nymphs) distribution on tomato plants in the four zones in banker plants only, Semi-IPM and IPM treatments, (B) schematic representation of the

greenhouse layout of the three respective treatments. White bars represent the proportion of $\mathrm{N}$. tenuis in zone 1, grey bars for zone 2, dark grey for zone 3, and black bars for zone 4. Banker plants were planted near zone 1 for all treatments while Violet-LEDs were set only in Semi-IPM and IPM treatments only on the opposite end of the greenhouse from the banker plants, adjacent to zone 4 .
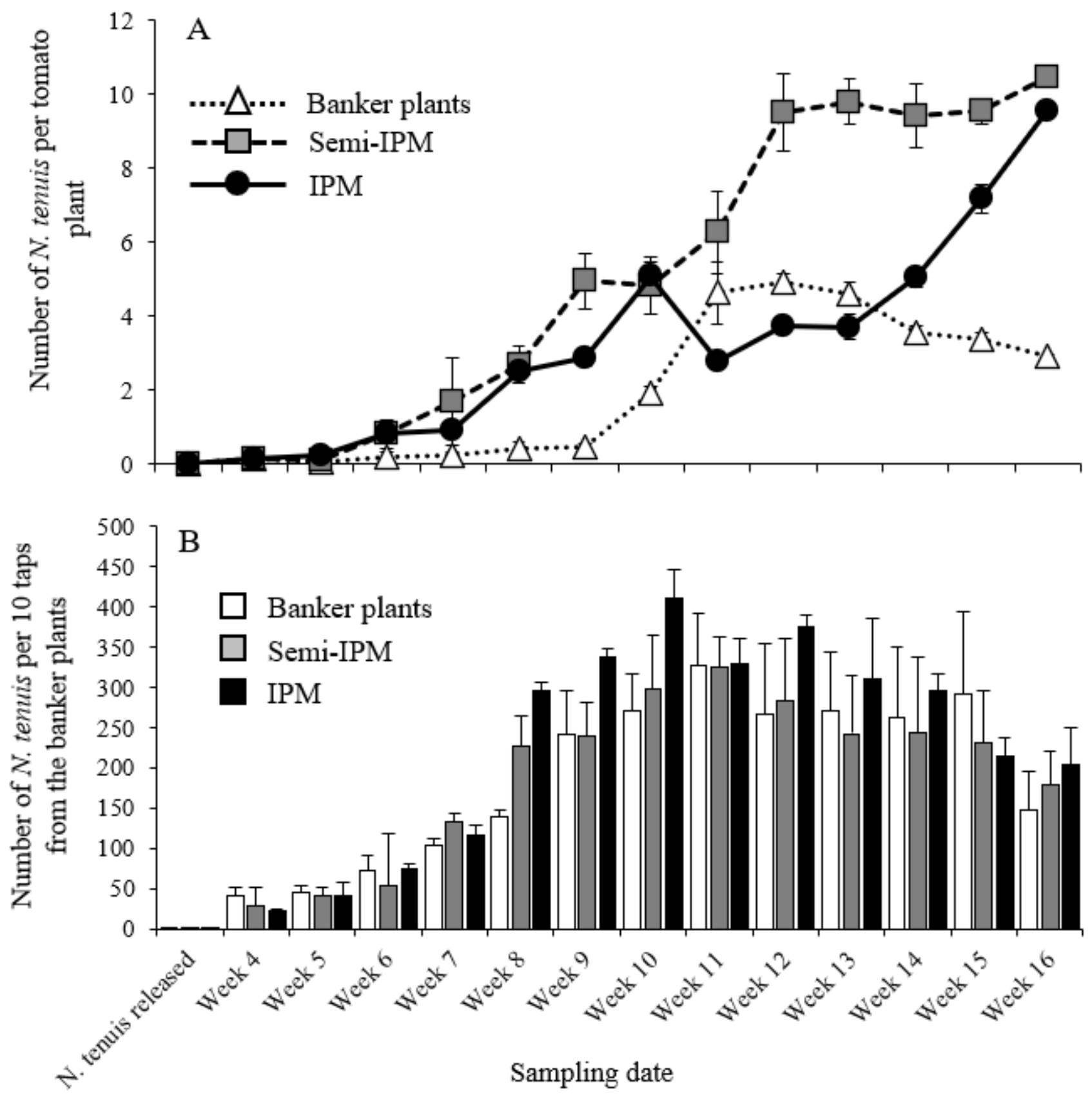

Figure 2 

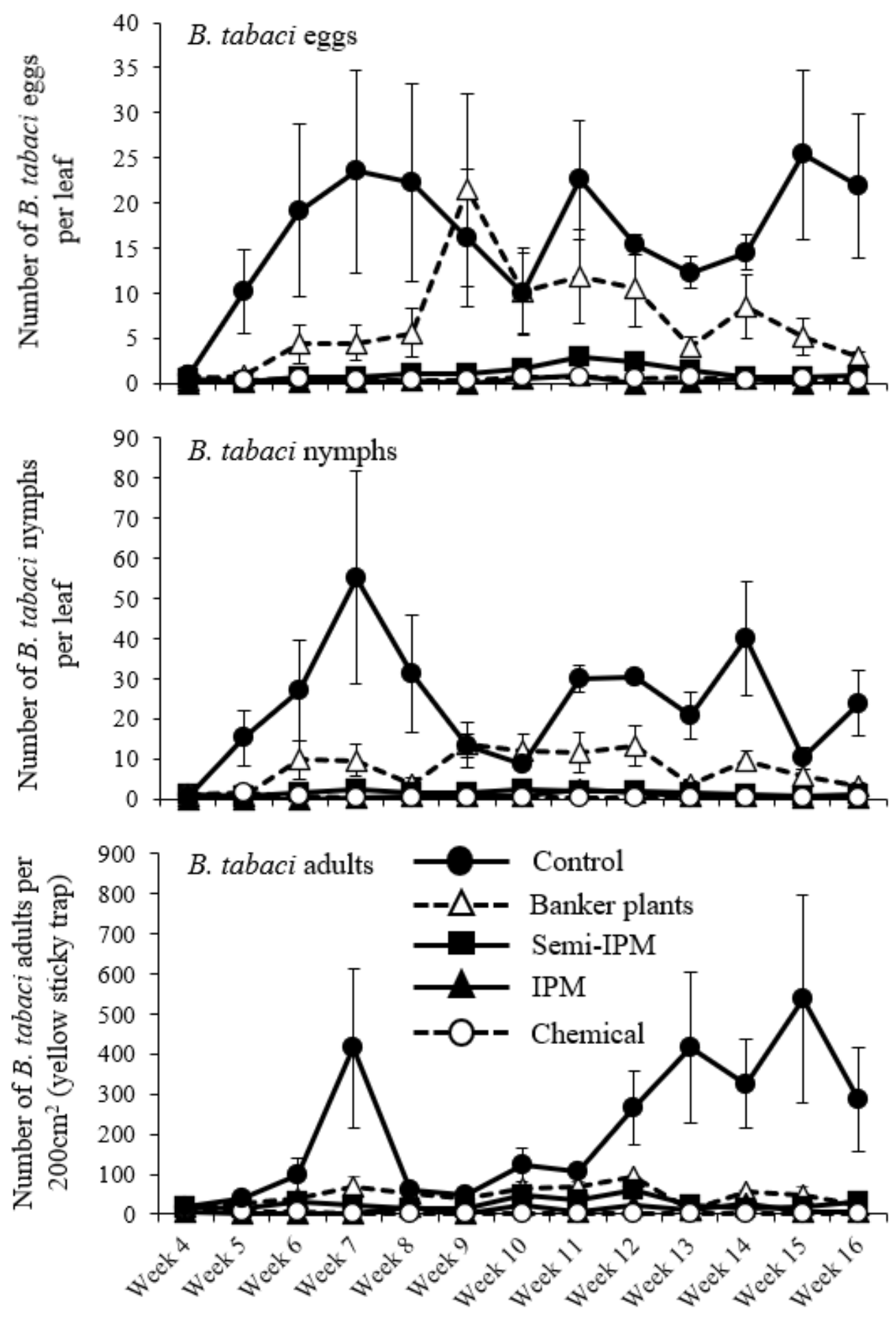

Sampling date

\section{Figure 3}

Mean $( \pm S D)$ number of Bemisia tabaci eggs, nymphs, and adults in the five treatments; Negative control, banker plants, semi-IPM, IPM and positive control treatment greenhouses. 


\section{Supplementary Files}

This is a list of supplementary files associated with this preprint. Click to download.

- WarietalSupplementarydata.pptx

- Tables.pptx 